\title{
Os institutos superiores de educação ontem e hoje
}

\section{The Higher Education Institutes yesterday and today}

\author{
Vera Lúcia Bazzo*
}

\begin{abstract}
RESUMO
Este trabalho propõe-se a discutir as políticas de formação de professores advindas da nova LDB e de suas subseqüentes regulamentações, especificamente aquelas que se referem à criação/recriação dos Institutos Superiores de Educação, confrontando-as, sempre que possível, com os antecedentes históricos que podem estar em sua origem ou mesmo, e contraditoriamente, ter lhe servido de modelo/inspiração. As reformas educacionais desta última década no Brasil pós-LDB - Lei n 9.394/96 - tiveram por objetivo conformar o sistema educacional à reestruturação produtiva e aos novos rumos do Estado, em pleno processo de globalização de receituário neoliberal no país. Neste contexto, a formação de professores colocou-se como questão central e estratégica para o governo, cujos formuladores de políticas públicas empenharam-se em produzir um grande número de novas regulamentações para o setor. Foi no conjunto dessas normas que, por meio da Resolução CNE 01/99, e com base no que anunciava o art. 62 da Lei ${ }^{\circ}$ 9.394/96, surgem/ressurgem os Institutos Superiores de Educação. O que significam no atual contexto educacional os Institutos Superiores de Educação e a que concepção de formação de professores tais instituições servem é o que se pretende discutir neste trabalho, tendo como referência a história da Educação, mais especificamente a história dos Institutos de Educação criados na década de 30. Suas semelhanças e diferenças, os diferentes contextos em que surgiram, suas finalidades, propostas e destino são algumas das perguntas que orientam e desafiam esta análise.

Palavras-chave: história da educação, formação de professores, Institutos Superiores de Educação.
\end{abstract}

* Professora adjunta do Centro de Ciências da Educação da Universidade Federal de Santa Catarina. 


\begin{abstract}
This study analyzes the teacher education policies that have been based on the new National Education Law (LDB) and its subsequent regulations, specifically those that refer to the creation and recreation of Higher Education Institutes, comparing them whenever possible with the historical precedents that may be at their origin, or even, and contradictorily, have served as a model and inspiration for them. The educational reforms in the past decade in Brazil according to the LDB Law 9394/96, as those which have taken place in other Latin American countries, sought to conform the educational system to the productive restructuring and to the new directions of the State in a full process of globalization under a neoliberal mold. In this context, the education of teachers is a central and strategic issue for the government. Public policy administrators have produced many new regulations for the sector. Based on these norms, Resolution CNE 01/99, and on art. 62 of Law 9394/96, the Higher Education Institutes arose or were recreated. This study analyzes the concept of teacher education that these institutes serve within the history of Education and more specifically the history of Educational Institutes created in the 1930s as a reference. The paper will compare the similarities and differences in these Institutes and the different contexts in which they arose, as well as their objectives and proposals.

Key-words: History of Education in Brazil, teacher education, Law of Guidelines and Bases for National Education, Higher Institutes of Education.
\end{abstract}

\title{
Introdução
}

Este trabalho tem por objetivo fazer uma breve análise sobre as políticas de formação de professores no Brasil a partir do fim dos anos 20 e início dos 30, período que marca o início da República Nova, até os dias de hoje, levando em conta o que dizem sobre o tema as diversas leis de diretrizes e bases da educação nacional, e tendo como foco principal a criação e as finalidades dos Institutos Superiores de Educação.

A trajetória das leis de diretrizes e bases da educação no país, embora seguindo cursos bastante diferenciados, terminava quase sempre por conseguir resultados semelhantes, conforme o contexto em que eram propostas, tendo como cenário a luta entre concepções de sociedade no limite das rela- 
ções sociais capitalistas, já que o projeto de uma sociedade socialista, embora presente e atuante em todas as discussões nacionais, apresentava poucas condições objetivas de se colocar como uma alternativa. Os avanços ou retrocessos materializados nessas leis foram, portanto, definidos pela correlação de forças entre conservadores e progressistas existente em cada momento histórico. Assim foi o embate entre conservadores e liberais nas décadas de 20 e 30 sobre a necessidade de se criar uma escola pública, gratuita, laica e universal; assim continuou a disputa nos anos que se seguiram à República Nova entre os que defendiam uma democracia pelo alto e vinculada estreitamente ao grande capital internacional, logo, defensores da privatização da educação, e os que defendiam uma democracia popular e participativa baseada na cidadania e no desenvolvimento nacional, vinculados, portanto, à idéia de que a educação deveria ser pública e se constituir em dever do Estado.

É importante mencionar como exemplo da duração e complexidade desses embates que a primeira Lei de Diretrizes e Bases da Educação Nacional (Lei n ${ }^{\circ} 4.024$ ) só foi sancionada em 1961, durante o governo João Goulart, vinte anos depois de iniciada sua discussão. As leis mais completas que se seguiram, e já refletindo a visão educacional do período mais fechado do regime autoritário pós 64, foram a Lei ${ }^{\circ} 5.540$ de 1968, sobre o Ensino Superior, e a Lei $\mathrm{n}^{\circ} 5.692$ de 1971 , para o $1^{\circ}$ e o $2^{\circ}$ graus, que nasceram dos gabinetes oficiais sem espaço para discussão, debate ou negociação, logo, foram mais rapidamente decretadas.

Embora não pareça, não foi muito diferente a história da mais recente LDB. Gestada durante os últimos anos da década de 80, momento em que o Brasil passava por um período de abertura democrática propício a grandes debates e conseqüente modificação dos processos constitutivos da democracia (em que pesem vários acontecimentos mundiais de natureza conservadora: queda do Muro de Berlim; colapso das experiências de socialismo real; virada conservadora dos governos de vários países da Europa; início da globalização econômica e anúncios do fim de história, para citar só alguns), sua discussão foi certamente favorecida pela reorganização gradativa da sociedade civil, entre elas as entidades ligadas à educação.

Já em 1984, durante a III CBE, em Niterói, e depois, na IV CBE, em Goiânia, e na Reunião Anual da Anped, ambas em 1986, ficara colocada a necessidade de se organizar o conhecimento produzido nas décadas de 70 e 80 em torno das bandeiras de luta e das reivindicações das entidades ligadas à educação em um documento que pretendia discutir e propor o conteúdo do capítulo da Educação para a Constituição. Era o momento da Constituinte. Com a promulgação da Constituição em 1988, essas mesmas entidades (Ande 
- Associação Nacional de Educação; Andes - Associação Nacional de Docentes da Educação Superior; Cedes - Centro de Estudos Educação e Sociedade; Anped - Associação Nacional de Pesquisa em Educação; CNTE - Confederação dos Trabalhadores em Educação; Sindicatos, entre outras) articularam-se em torno de parlamentares progressistas para deflagrar o processo de discussão sobre a necessidade de dotar o país de uma nova lei de diretrizes e bases da educação (BAzzo, 1991).

A partir dessa compreensão,

é no contexto das lutas travadas pelas forças comprometidas com uma democracia e cidadania efetivas, nos debates da constituinte e na formulação do novo projeto da Lei de diretrizes e Bases da Educação (LDB), que o campo educativo capitaliza as propostas alternativas, gestadas na sociedade ao longo dos anos 70 e 80 , em torno do ideário de uma escola pública, gratuita, unitária, laica e universal e da institucionalização da gestão democrática. (FRIGOTTO, 2001, p. 59)

Depois de amplamente debatido pelos educadores, que não só participaram de sua elaboração como tinham, à época, representantes no Congresso que os ouviam e efetivamente assimilavam grande parte de suas contribuições, o projeto chegou à Câmara dos deputados, onde tramitou por quase quatro anos, trocando de relator e recebendo muitas mudanças por meio de emendas, de acordo com a correlação de forças que se estabeleciam, cada vez mais conservadoras, à medida que mudava a composição das bancadas. (SCHEIBE; BAZZO, 2001)

Ainda conforme FRIGOTTO (2001, p. 60), “a transição, a partir dos anos 90 , é abortada por um projeto profundamente conservador, centrado na ditadura do grande capital e da ideologia neoliberal do mercado autodeterminado".

Dessa forma, em 1992, quando o projeto da Câmara ("o que talvez tenha sido o mais democrático e aberto método de elaboração de uma lei de que se tem notícia no Congresso Nacional", conforme palavras do deputado Jorge Hage - PSDB/BA, relator) estava prestes a ir à votação, o então senador Darci Ribeiro, numa clara intervenção favorável ao governo, apresentou uma outra formulação, muito próxima às propostas do Ministério da Educação naquele momento, atropelando a tramitação anterior e adequando o texto legal à orientação política dominante. Esta proposta, bastante diferente da que tramitava na Câmara, acabou sendo votada e aprovada em dezembro de 1996, tornan- 
do-se a Lei de Diretrizes e Bases da Educação Nacional - Lei n ${ }^{\circ}$ 9.394/96 (SCHEIBE; BAZZO, 2001).

Foi no texto e contexto desta lei que reapareceram os Institutos Superiores de Educação como locus para a formação de professores.

\section{A formação de professores nos institutos superiores de educação e nas escolas de professores nos anos $30^{1}$}

É antiga no Brasil a aspiração dos educadores pela formação de professores em nível superior, inclusive para os anos iniciais da Educação Fundamental, a antiga Escola Primária, principalmente nos grandes centros, onde se concentravam os intelectuais e as maiores escolas.

Assim, desde o início do século XX, foram desenvolvidos cursos pósnormais, instalados junto à Escola Normal da Praça, em São Paulo, com o objetivo de promover o aperfeiçoamento de professores. Esses cursos foram a origem dos cursos superiores de formação do professor secundário implantados pela reforma Francisco Campos em 1931. A Escola Normal de então foi transformada em Instituto Pedagógico de São Paulo e em seu âmbito conviviam o Curso Normal, que formava os professores para as primeiras séries, o chamado Curso Primário, e o curso de aperfeiçoamento, que formava especialistas em nível pós-normal, ou seja, os inspetores, delegados de ensino, diretores e professores da Escola Normal. Mais tarde, em 1933, foi transformado em Instituto de Educação Caetano de Campos, que passou a também formar os professores para o nível secundário e desenvolver pesquisas na área. Foi essa instituição que, em 1933, tornou-se o Instituto de Educação, depois incorporado à Universidade de São Paulo (USP), onde veio a ser uma unidade universitária de preparação de professores para todos os graus de ensino (BREZINSKI, 1999).

Com base no que defendiam os Pioneiros da Escola Nova no "Manifesto dos Pioneiros"(1932) a respeito da necessidade de a formação de professores de todos os níveis ser feita na universidade, um Instituto de Educação também existiu na mesma época no Rio de Janeiro, criado por Anísio TEIXEIRA,

\footnotetext{
${ }^{1}$ Optamos por deixar os acentos originais conforme a ortografia da época.
} 
em 1934, quando foi titular da Secretaria de Educação e Cultura do Distrito Federal. Assim, no organograma do "Departamento de Educação", em lugar de destaque e com a mesma importância do "Instituto de Pesquisa", figurava o "Instituto de Educação", "a cujo cargo, por sua principal escola, a Escola de Professôres (sic) (depois Escola de Educação), em nível universitário, está a formação do magistério geral especializado, bem como do funcionalismo técnico de educação necessário ao sistema" (TEIXEIRA, 1953, p. 135).

É o próprio Anísio teIXeIRA, (1953, p. 95), quem discute a importância da formação de professores em nível universitário, como a justificar a criação da estrutura acima proposta:

(...) o segrêdo da formação do professor está em integrar, o mais intimamente que fôr possível, os materiais e as técnicas da sua arte de ensinar. Como na pintura e nas demais belas-artes. O dualismo da preparação acadêmica e da preparação profissional só pode trazer confusão e ineficiência.

O estudo da matéria e o estudo da teoria da educação e dos métodos devem ser perfeitamente integrados, dando-se muito mais relêvo ao ensino da matéria sob o ponto de vista das necessidades do professor e do ensino, do que aos cursos gerais de educação.

A preparação do professor não dispensa a formação científica que os respectivos cursos lhe podem dar, mas não fica aí o seu aparelhamento técnico. Segundo Bagley, o professor deverá ser preparado nos seguintes pontos:

1. conhecimento completo e profundo da matéria que vai ensinar;

2. apreciação aguda da significação dessa matéria para a vida humana;

3. desejo vivo e ardente de que outros conheçam essa matéria e a apreciem;

4. compreensão e conhecimento inteligente e simpático das dificuldades que o aluno encontra para se tornar senhor da matéria;

5. conhecimento de tôdas as técnicas e processos para melhor vencer essas dificuldades.

Em 1939, a Escola de Professores do Instituto de Educação do Rio de Janeiro foi incorporada por seu criador à Universidade do Distrito Federal e tinha entre seus principais objetivos a formação de professores e o desenvolvimento da pesquisa em educação. 
Embora a Universidade do Distrito Federal da forma como fora idealizada por Anísio teIXEIRA não tenha vingado por muito tempo, por motivos políticos, a experiência de formar professores para todos os graus de ensino em uma escola única de estrutura verticalizada em nível universitário deixou sementes para sempre.

Como dizia, então, Anísio teiXeIra (1953, p. 181-186),

É em obediência às solicitações imperiosas de uma formação aprimorada do mestre, bem como à necessidade de determinar finalidades precisas e uniformes para os estabelecimentos de ensino, que se elevou, definitivamente, o preparo dos professores ao nível universitário, e se organizaram, na Escola de educação, que se segue à Escola Secundária, cursos nitidamente profissionais para o preparo do mestre.

(...) Dado o caráter da arte de ensinar, diverso do da arte de engenharia ou da medicina, não se podem separar os estudos das chamadas ciências da educação, dos estudos das matérias que se vão diretamente ensinar. Os cursos técnicos de educação devem integrar-se profundamente nos próprios cursos de matérias de ensino. Esses cursos, que devem ser dados 'do ponto de vista do ensino dessas matérias', constituem o núcleo da formação do professor.

É esse um ponto de imensa importância, por isso mesmo que aí se podem estabelecer os dualismos e as confusões funestas à informação adequada do mestre.

(...) A ciência da educação, que existe até agora, deve ser levada ao conhecimento do aluno nos próprios cursos de aritmética, de geografia, de história, de qualquer matéria ou em conexão com estes.

(...) A Escola de educação não tem, assim, outra pretensão senão a de ser uma escola profissional, em que se preparam os mestres, fazendo-os aprender e praticar diretamente as matérias que irão ensinar.

(...) A nossa escola combina as duas tendências de que falávamos, reconhecendo a necessidade de dar ao professor orientação científica no seu trabalho, sem perder, entretanto, a visão de que o magistério é mais uma arte prática do que uma ciência aplicada.

(...) Ao lado dessa escola de preparação de mestres e sôbre ela, está a erguer-se o centro de pesquisas educacionais, que deverá constituir, no futuro, um dos focos de irradiação nacional das ciências da educação.

As raízes de muitas das questões que ainda hoje se colocam para os educadores a respeito da formação de professores, certamente, estão presen- 
tes nas reflexões dos Pioneiros da Escola Nova e nas experiências dos Institutos Superiores de Educação / Institutos Pedagógicos / Escolas de Professores surgidas nos anos 30 .

\section{O lugar estratégico da formação de professores nas reformas educacionais}

As reformas educacionais em todos os tempos têm por objetivo adequar o sistema educacional ao modelo de sociedade e de acumulação proposto em um dado momento histórico por reformas do próprio Estado. A escola como um dos aparelhos de formação de hegemonia, no dizer de Gramsci, tem papel de importância reconhecida pelo sistema na busca do consenso em torno dessas reformas, e o professor, nesse contexto, aparece como o agente de mudança, responsável pela realização do ideário educacional de cada época. Assim, na última década, no Brasil, bem como em outros países da América Latina, as reformas que se processaram na educação visaram a conformar o sistema educacional ao processo de reestruturação produtiva e de ajuste subordinado ao mercado mundial que, como diz FRIGOTTO (2001, p. 63), tem por objetivo "afirmar o mercado como árbitro fundamental na regulação das relações econômicas, sociais, culturais e educacionais e, como conseqüência, promover um profundo atrofiamento da esfera pública".

Com essa compreensão, entende-se o grande interesse do governo em derrotar o projeto de LDB que tramitava na Câmara dos Deputados e que havia sido a síntese possível conseguida pelo movimento dos educadores a partir de muita negociação. Era de fundamental importância aprovar o projeto minimalista e afinado com as propostas do poder instalado que saíra da lavra do senador Darcy Ribeiro.

A aprovação da nova Lei de Diretrizes e Bases da Educação Nacional (LDB), Lei $\mathrm{n}^{\circ}$ 9.394/96, em dezembro de 1996, representou um marco significativo na institucionalização das reformas educativas requeridas pelo processo de reforma do Estado em andamento no país. No centro delas coloca-se estrategicamente a questão da formação dos profissionais da educação.

É nessa Lei, sob o Título VI, art. 61 a 67 - Dos Profissionais da Educação -, que a determinação mais importante para a análise a que nos propomos neste trabalho está contida. Diz a Lei em seu art. 62: 
a formação de docentes para atuar na educação básica far-se-á em nível superior, em curso de licenciatura, de graduação plena, em universidades e institutos superiores de educação, admitida, como formação mínima para o exercício do magistério da educação infantil e nas quatro primeiras séries do ensino fundamental, a oferecida em nível médio, na modalidade normal (grifo nosso).

A criação dos Institutos Superiores de Educação em sua versão atual precisa ser vista, portanto, como uma proposição no interior das políticas educacionais em implantação e compreendida à luz de uma conjuntura que aprofunda a lógica de exclusão social do projeto econômico vigente, sob o manto do mercado regulador.

É neste contexto que os formuladores de políticas públicas empenharam-se em produzir um grande número de novas regulações para o setor, dentre as quais destaca-se a Resolução CNE 01/99, que, com base no art. 62 da LDB n ${ }^{\circ}$ 9.394/96 acima referido, recria os Institutos Superiores de Educação, acompanhados dos Cursos Normais Superiores, ambos com estatuto de locais privilegiados para a formação de professores: para a Educação Infantil e anos iniciais da Educação Básica, o Curso Normal Superior; para os demais, o Instituto Superior de Educação.

O que têm de semelhanças ou de diferenças essas agências de formação de professores e as anteriormente mencionadas é o que se pretende tentar discutir agora.

\section{Os institutos superiores de educação hoje - o reverso da medalha}

Se nos anos 30 a afirmação de que os professores de todos os níveis deveriam ser formados em nível superior era uma idéia revolucionária para o grau de desenvolvimento da sociedade e das forças produtivas da época, hoje, mais de 70 anos depois, certamente a manutenção da formação de professores para os anos iniciais da Educação Fundamental e Educação Infantil em nível secundário como aparece no art. 62 da Lei n 9.394/96, “(...) admitida, como formação mínima para o exercício do magistério da educação infantil e nas quatro primeiras séries do ensino fundamental, a oferecida em nível médio, na modalidade normal”, embora adequada à desalentadora realidade edu- 
cacional do país, representa um atraso secular, ao mesmo tempo em que reafirma a tradição de desqualificação desses profissionais em nosso país.

Foi a Lei $n^{\circ} 5.692$ de 1971 que propôs, depois de tanto tempo, e pela primeira vez em uma lei de âmbito nacional, a formação do professor primário em nível universitário em cursos de licenciatura plena, ao criar um modelo de organização que lhe permitia acumular gradativamente anos de escolaridade para atuar em séries cada vez mais avançadas do sistema escolar. Para viabilizar este modelo, a Lei previa vários níveis de formação, (surgem assim as Licenciaturas curtas) correspondendo a cada uma o respectivo exercício profissional, vinculando o salário do professor ao seu nível de formação.

O que poderia ser um avanço, ao tornar compulsória a profissionalização do professor das séries iniciais em nível médio - nos cursos chamados de Magistério - transformou-o numa das habilitações do ensino de segundo grau, descaracterizando as Escolas Normais e os Institutos de Educação, onde tal formação era feita, sem dúvida com melhor qualidade.

Quanto à formação de professores para as séries posteriores $\left(5^{\mathrm{a}}\right.$ à $\left.8^{\mathrm{a}}\right) \mathrm{e}$ para o $2^{\circ}$ grau, a Lei $n^{\circ} 5.540$ - Lei da Reforma Universitária - mesmo instalando as Faculdades/Centros de Educação com a finalidade de neles centralizar a formação dos profissionais da educação, não conseguiu superar o modelo vigente das licenciaturas, isto é, os cursos $3+1$, em que as disciplinas da educação, conhecidas como as pedagógicas, com duração prevista para um ano, justapunham-se às disciplinas de conteúdo específico ou, como se dizia, de conteúdo científico, cuja duração era de três anos.

A Lei de Diretrizes e Bases de 1996, entre outras modificações, no tema da formação dos profissionais da educação, extinguiu as Licenciaturas Curtas, fracassada experiência promovida pela lei anterior que pretendia formar professores para o $1^{\circ}$ grau ( $5^{\mathrm{a}}$ à $8^{\mathrm{a}}$ séries $)$ em cursos aligeirados e com o mínimo de conteúdo, seja da área específica seja das ciências da educação, ministrados como parte inicial nos primeiros anos dos cursos de Licenciatura plena e, com isso, aboliu os avanços progressivos de escolaridade com o conseqüente direito ao exercício profissional. Manteve e expandiu, no entanto, a possibilidade de aproveitamento de estudos e de experiências profissionais anteriores para a integralização dos cursos de formação de professores.

$\mathrm{O}$ (re)surgimento dos Institutos Superiores de Educação entre as instituições que poderiam formar os profissionais da educação para todos os níveis da Educação Básica foi, entretanto, a maior novidade que esta lei trouxe. A princípio solto e descontextualizado no interior do art. 62, parecendo mais um lapso da memória ou o fruto de alguma nostalgia de seu redator, com a Resolução 01/CNE/CP/99 que regulamentou tal instituição, os ISEs passa- 
ram a ser o motivo de muitas preocupações para os educadores que ao longo dos anos vêm defendendo uma formação sólida e exigente, aliada à pesquisa e em cursos de licenciatura plena, em instituições universitárias.

Pela nova lei e por toda a legislação complementar que a sucedeu, as atribuições dos Institutos Superiores de Educação são bastante amplas no que diz respeito à formação dos professores e claramente esvaziadoras das responsabilidades e tarefas das faculdades/centros de educação das universidades, indicando, mais uma vez, o risco de desprofissionalização ainda maior, além da desvalorização que uma formação fora da universidade e com exigências muito menores no nível de qualificação de seus mestres poderá acarretar.

Assim, a criação dos Institutos Superiores de Educação, no contexto dessa lei, significa um rebaixamento na hierarquia universitária com tudo o que isto implica em perda de qualidade e mesmo de prestígio para a formação dos profissionais da educação.

Embora em cada momento histórico houvesse um grande esforço dos intelectuais comprometidos com a qualidade da escola pública e com a formação de seus profissionais em nível universitário, é possível dizer que estratégias de redução do conhecimento e da ação pedagógica do professor, acompanhada de baixos salários e quase nada de profissionalização, têm sido uma constante ao longo das reformas educacionais. Para marcar definitivamente esta discriminação, a (re)criação, hoje, de instituições de diferentes qualidades e de menor valorização para a formação dos profissionais da educação, como parecem ser os Institutos Superiores de Educação (ISE) e o Curso Normal Superior, descaracteriza profundamente a feição profissional dos docentes no Brasil.

Os Institutos Superiores de Educação, propostos pela atual legislação educacional para serem a instituição formadora de professores por excelência, não por acaso aparecendo na última posição na hierarquia das instituições de ensino superior, diferentemente de seus similares da década de 30, representam uma preocupante preferência pela formação desses profissionais fora da universidade, em locais onde a pesquisa e a conseqüente produção de conhecimento poderão passar ao largo, dadas às baixas exigências de qualificação do corpo docente que a lei estabeleceu para a criação dos ISEs. Longe estarão, certamente, de serem os irradiadores dos novos conhecimentos sobre a educação e o ensino, como anunciava Anísio TEIXEIRA (1953, p. 186) em 1934, ao falar da Escola de Professores do Instituto de Educação do Distrito Federal: 
Ao lado dessa escola de preparação de mestres e sobre (sic) ela está a erguer-se o centro de pesquisas educacionais, que deverá constituir-se, no futuro, um dos focos de irradiação nacional das ciências da educação.

As diferentes políticas que, a partir dessa regulamentação, estão postas para a formação do professor e que são motivo de nossas críticas e intervenções, quais sejam: a configuração dos cursos de licenciatura (Res. CNE/CP/ 01/2002 e Res. CP 02/2002); as determinações do Parecer 133/2001, que impedem os Cursos de Pedagogia de IES não universitárias de formar professores da educação Infantil e dos anos iniciais da educação Fundamental; a ênfase no treinamento em serviço, em detrimento da formação inicial de qualidade; a utilização da modalidade de educação à distância como forma de aligeirar e baratear a formação inicial; a insistência na certificação das competências - todas elas evidenciam a lógica mercantilista, racionalista e pragmática que tomou conta da nação, e têm como objetivo responder muito mais à rápida modificação dos índices educacionais do que à necessidade da formação de profissionais com capacidade de colaborar com as mudanças que o país está a exigir.

Contrapondo-se a todos esses movimentos conservadores propostos pelas políticas anunciadas, a Associação Nacional pela Formação dos Profissionais da Educação (Anfope), liderando as demais entidades de educadores, no documento final de seu IX ENCONTRO NACIONAL em 1998, já apresentava sinteticamente sua posição frente às Diretrizes Curriculares para os cursos de formação dos profissionais da educação, na qual salientava os seguintes pontos:

As Universidades e suas Faculdades de Educação deverão ser os locais prioritários para a formação dos profissionais da educação para atuar na educação básica e superior;

- É necessário repensar as estruturas das Faculdades e a organização dos cursos de formação em seu interior, no sentido de superar a fragmentação entre as habilitações no curso de pedagogia e a dicotomia entre a formação dos pedagogos e dos demais licenciados, considerando-se a docência como a base de identidade profissional de todos os profissionais da educação;

- É importante estabelecer uma Base Comum Nacional para esta formação, integrada a uma formação específica para as diversas áreas de atuação. Os eixos norteadores estabelecidos para essa Base Comum Nacional serão os seguintes: sólida formação teórica e 
interdisciplinar; unidade entre teoria e prática, que implica em assumir uma postura em relação à produção de conhecimento que perpassa toda a organização curricular e que não divorcia a formação do bacharel e do licenciado, embora considere suas especificidades; gestão democrática da escola; o compromisso social e ético do profissional da educação na superação das injustiças sociais, da exclusão e da discriminação, na busca de uma sociedade mais humana e solidária; trabalho coletivo e interdisciplinar; articulação da formação inicial e continuada.

Os princípios para a Organização Curricular, então defendidos e socializados, indicaram:

- a formação para o humano, forma de manifestação da educação omnilateral dos homens;

- a docência como base da formação profissional de todos aqueles que se dedicam ao estudo do trabalho pedagógico;

- o trabalho pedagógico como foco formativo;

- a sólida formação teórica em todas as atividades curriculares - nos conteúdos específicos a serem ensinados pela escola básica e nos conteúdos especificamente pedagógicos;

- a ampla formação cultural;

- a criação de experiências curriculares que permitam o contato dos alunos com a realidade da escola básica, desde o início do curso;

- a incorporação da pesquisa como princípio de formação;

- a possibilidade de vivência pelos alunos de formas de gestão democrática;

- o desenvolvimento do compromisso social e político da docência;

- a reflexão sobre a formação do professor e sobre suas condições de trabalho;

- a avaliação permanente dos cursos de formação dos profissionais da educação como parte integrante das atividades curriculares e entendida como responsabilidade coletiva a ser conduzida à luz do projeto político-pedagógico de cada curso em questão.

A partir das críticas sempre reafirmadas nos documentos oficiais, justificadoras da criação dos Institutos Superiores de Educação, de que as universidades não cumpriam bem a tarefa de formar professores, preocupadas primordialmente com os cursos de bacharelado e com a produção de conhecimento de ponta em cada área, os Centros/Faculdades de educação e todos os responsáveis pela formação dos profissionais da educação internamente às universidades, isto é, vinculados aos cursos de licenciaturas, perce- 
beram que para avançar na discussão da formação dos profissionais da educação era necessário criar uma instância em que essas questões fossem tratadas. Surgiram, assim, ainda antes da aprovação da LDB n ${ }^{\circ} 9.394$, logo, antes da criação dos ISEs, os Fóruns de Licenciaturas nas universidades.

Nesse sentido, ficou claro para o movimento dos educadores que era preciso considerar mais significativamente a articulação com esses novos parceiros criados nas IES, com o objetivo de melhor integrar as áreas de conteúdos específicos com a área de formação pedagógica. Assim, passou-se a defender de maneira mais enfática a necessidade de se considerar esse espaço como o local para definições conjuntas sobre os projetos de formação de professores das IES, levando em conta as diversas e bem sucedidas experiências já desenvolvidas no país.

Em contraposição às novas diretrizes, que se delineavam com ênfase instrumentalizadora e praticista, reduzindo cada vez mais os conteúdos formativos de natureza teórico-científica, os educadores em torno às suas associações passaram a defender um curso de formação de profissionais da educação com duração mínima de quatro anos e com 3.200 horas, apesar de as atuais Diretrizes Curriculares para a formação do profissional para o magistério da Educação Básica no Brasil, aprovadas, como mencionado anteriormente, por recente legislação (CNE. Resolução CNE/CP 1/2002. Diário Oficial da União, Brasília, 4 de março de 2002, seção 1, p. 8, e Resolução CNE/CP 2/2002. Diário Oficial da União, Brasília, 4 de março de 2002, seção 1, p. 9) reafirmarem a tendência a diminuí-los para 2.800 horas e três anos de duração.

Além disso, essas mesmas diretrizes determinam a constituição de um "Sistema de Formação, Avaliação e Certificação Profissional Baseado em Competências", redirecionando a perspectiva pedagógica a ser adotada no que concerne aos programas, conteúdos e métodos de ensino, avaliação e desempenho dos professores.

Essas diretrizes partem do princípio de que a formação de professores, para atender às necessidades de formação do alunado da Educação Básica brasileira, deve considerar, acima de tudo, o conjunto das competências necessárias à atuação profissional (Res. CNE/CP1, de 18 de fevereiro de 2002, art. $\left.4^{\circ}\right)$. Na sua concepção, no desenvolvimento e na abrangência dos cursos de formação é fundamental, portanto, que se busque "adotar essas competências como norteadoras, tanto da proposta pedagógica, em especial do currículo e da avaliação, quanto da organização institucional e da gestão da escola de formação".

O significado da noção de competências como concepção nuclear para orientar a formação representa uma concepção individualista na sua essência 
e imediatista em relação ao mercado de trabalho. Logo, é limitada e limitadora em relação à perspectiva da formação humana.

Diz ainda essa legislação que a formação deverá ser realizada em processo autônomo, em curso de licenciatura plena, numa estrutura com identidade própria, embora mantida, quando couber, (grifo nosso) "estreita articulação com institutos, departamentos e cursos de áreas específicas"(Res. $\mathrm{CNE} / \mathrm{CP} 1$, de 18 de fevereiro de 2002, art. $7^{\circ}$ ). Esta concepção, historicamente defendida pelos educadores desde Anísio teIXEIRA, conforme se pôde observar no início deste trabalho, é a parte boa a se conservar, excluindo-se o "quando couber" e insistindo com todo o restante. É importante abrigar esta concepção que traz para a licenciatura identidade, integralidade e terminalidade própria, valorizando a formação do professor como profissional do ensino, o que é um avanço na sua qualificação técnico-científica, se comparada com uma formação apenas complementar ao bacharelado. O que se tem que rechaçar é a afirmação de que para isso acontecer, a formação deverá ser feita em locus distinto das universidades. Isso traria, ao nosso ver, a possibilidade de se ampliar o fosso entre a formação do bacharel e a do licenciado, principalmente se esta última for destinada aos Institutos Superiores de Educação e, conseqüentemente, divorciada da produção do conhecimento específico da área.

Ainda no art. $7^{\circ}$ dessas diretrizes, a legislação determina que as instituições de formação deverão trabalhar em interação sistemática com as escolas de educação básica, desenvolvendo projetos de formação compartilhados, prevendo inclusive a formação dos formadores, incluindo na sua jornada de trabalho tempo e espaço para as atividades coletivas dos docentes do curso, estudos e investigações sobre as questões referentes ao aprendizado dos professores em formação. As escolas de formação deverão garantir recursos pedagógicos como biblioteca, laboratórios, videoteca, recursos de tecnologias da informação e da comunicação, com o que todos concordamos e queremos ver implementado.

Outra definição importante que traz a nova legislação tem a ver com a determinação de que a prática, na matriz curricular, não poderá ficar reduzida a um espaço isolado, que a restrinja ao estágio supervisionado, desarticulado do restante do curso. A prática, reza o art. 12, deverá estar presente desde o início do curso e permear toda a formação do professor, no interior "das áreas ou das disciplinas que constituírem os componentes curriculares de formação, e não apenas nas disciplinas pedagógicas". Isto também faz parte de nossa concepção sobre a prática, desde que fique clara a relação teoria-prática e não se caia no praticismo por ele mesmo. 
Finalmente, e o que compromete todas as outras boas intenções da referida resolução, a possibilidade de realização dos cursos de licenciatura numa graduação que pode ser integralizada em 3 anos de curso aponta mais uma vez para a descaracterização profissional do docente já produzida, ao longo da história, por estratégias de redução do conhecimento na formação do professor e, conseqüentemente, de sua ação pedagógica. Somem-se a isto as precárias condições de trabalho e a perda crescente do poder aquisitivo do salário para se ter um panorama do que poderá acontecer em prazo relativamente curto com a carreira do magistério e com a qualidade da educação no país.

Fecha-se, assim, o ciclo, ontem e hoje. O Instituto Superior de Educação surgido da efervescência cultural e política dos anos 30 é substancialmente diferente do Instituto Superior de Educação recriado pela Lei ${ }^{\circ}$ 9.394/ 96 muito mais pelo seu contexto histórico do que pelo seu texto elaborador. Distingue-se o primeiro, também e principalmente, pela sinceridade com que seus formuladores defendiam uma formação humanística mais completa e em nível superior para todos os professores como reconhecimento da importância de tais profissionais no processo de educação do povo que naquele momento se urbanizava e era necessário para ocupar os postos de trabalho da novel industrialização do país. São parecidos como expressão de hegemonia num dado momento. O segundo, portanto, é o reflexo das políticas públicas para a educação que acompanham o caudal das reformas do Estado deste projeto neoconservador que todos queremos sepultar.

\section{REFERÊNCIAS}

ANFOPE. Associação Nacional pela Formação dos Profissionais da Educação. ENCONTRO NACIONAL, 9., Documento final. Brasília: 1998.

ENCONTRO NACIONAL, 10., Documento final. Brasília, 2000.

ENCONTRO NACIONAL, 11., Documento gerador. Florianópolis, 2002.

BAZZO, V. L. LDB - O que muda e o que permanece na nova proposta? Cadernos do CED, Florianópolis, n. 17, p. 60-65, jun. 1991.

BRASIL/CNE/CP. Resolução CP, n. 01, 30 jul. 1999. Dispõe sobre os Institutos superiores de Educação. 
Parecer CP, n. 009, 08 maio 2001. Institui as DCN para a Formação de Professores da Educação Básica, em nível superior, curso de licenciatura, de graduação plena.

. Parecer CP, n. 001, 18 fev. 2002. Institui as DCN para a Formação de Professores da Educação Básica, em nível superior, curso de licenciatura, de graduação plena.

Parecer $C P$, n. 002, 19 fev. 2002. Institui a duração e a carga horária dos cursos de licenciatura, de graduação plena, de formação de professores da Educação Básica em nível superior.

BRZEZINSKI, I. Embates na definição das políticas de formação de professores para a atuação multidisciplinar nos anos iniciais do Ensino Fundamental: respeito à cidadania ou disputa pelo poder? Educação \& Sociedade, Campinas, ano 20, n. 68, p. 88108, dez.1999.

FRIGOTTO, Gaudêncio. Reformas educativas e o retrocesso democrático no Brasil nos anos 90. In: LINHARES, Célia (Org.). Os professores e a reinvenção da escola. São Paulo: Cortez, 2001. p. 57-80.

SAVIANI, D. A nova lei da educação: LDB - trajetória, limites e perspectivas. 3. ed. Campinas: Autores Associados, 1997.

SCHEIBE, L.; BAZZO,V. L. A trajetória das políticas públicas de formação docente no país. Itajaí: Contra Pontos, ano 1, n. 1, p. 91-103, jan./jun.2001.

. Políticas governamentais para a formação de Professores na atualidade. $R e$ vista Brasileira de Ciências do Esporte, Campinas, v. 22, n. 3, p. 9-21, maio 2001.

TEIXEIRA, A. S. Educação para a democracia: introdução à administração educacional. 2 ed. São Paulo: Editora Nacional, 1953. Biblioteca Pedagógica Brasileira, série 3 , v. 57.

Texto recebido em 22 abr. 2003

Texto aprovado em 03 set. 2003 